Rubens Correia Junior ${ }^{1,2}$

Carla Arena Ventura ${ }^{3}$

\title{
O TRATAMENTO DOS PORTADORES DE TRANSTORNO MENTAL NO BRASIL - DA LEGALIZAÇÃO DA EXCLUSÃO À DIGNIDADE HUMANA
}

The treatment of patients with mental disorders in Brazil

- from the legalization of exclusion to human dignity

${ }^{1}$ Universidade Presidente Antônio Carlos. Uberaba/MG, Brasil.

${ }^{2}$ Instituto Paulista de Estudos Bioéticos e Jurídicos. Ribeirão Preto/SP. Brasil.

${ }^{3}$ Escola de Enfermagem de Ribeirão Preto, Universidade de São Paulo. Ribeirão Preto/SP, Brasil.

Correspondência: Rubens Correia Junior. E-mail: rubensjrconsultor@gmail.com.

Recebido em: 13/03/2013. Aprovado em: 09/08/2013. 


\section{RESUMO}

Este artigo tem como objetivo traçar a trajetória histórico-cultural e social do tratamento dos portadores de transtorno mental com ênfase no Brasil, realçando as significativas transformações que levaram um sistema pautado na referência hospitalar a um sistema interdisciplinar de atenção diversificada e comunitária. Partindo dessa experiência, o presente estudo realça as políticas públicas de saúde mental, contrapondo-as às ideologias políticas e sociais de cada momento histórico. Evidencia também a legalização da exclusão, perpetuada pelo dualismo estigmatizante e rotulador entre "normais" e "anormais", presente historicamente nas políticas públicas pré-Constituição de 1988. Então, este artigo destaca a busca pela dignidade humana cunhada pós-Constituição de 1988, tendo como alicerce o propósito de efetivação dos direitos humanos e a concretização das garantias e direitos fundamentais do cidadão diante da Lei $10.216 / 2001$. Por fim, esta reflexão teórica contrapõe o direito e a saúde, discutindo se as premissas constitucionais de 1988 estão sendo efetivadas nas políticas públicas voltadas ao tratamento de portadores de transtorno mental.

\section{Palavras-chave}

Dignidade Humana; Lei 10.216/2001; Portadores de Transtorno Mental; Saúde Mental.

\section{ABSTRACT}

This article aims at describing the historical, cultural and social evolution of the treatment for patients with mental disorders, emphasizing the Brazilian experience and the significant transformations which drove a system based on hospitals to a community based care network. From this experience, this article highlights the mental health public policies in view of the social and political ideologies of each historical moment. Authors argue about the legalization of exclusion, perpetuated through the stigma which distinguished between "normal" and "abnormal" and was historically present in public policies developed in the period prior to the 1988 Brazilian Constitution. Then, this paper consolidates the search for the principle of human dignity which is consolidated with the 1988 Constitution, based on the purpose of implementing human rights and making fundamental rights concrete through the Brazilian Law 10.216/2001. At the end, this article contrasts law and health discussing if the 1988 constitutional premises are being implemented in the public policies to the treatment of patients with mental disorders.

\section{Keywords}

Brazilian Law 10.216/2001; Human Dignity; Mental Health; Patients With Mental Disorders. 


\section{Introdução}

No decorrer dos séculos, a compreensão da loucura pela sociedade e pela ciência passou por grandes alterações, tendo uma variação de significados, sentidos e concepções no imaginário social ${ }^{1}$. Nesse contexto, os sentidos e concepções foram se adequando aos sistemas e estruturas sociais de cada época e a forma de tratamento dos sujeitos considerados loucos passou por importantes alterações e adaptações durante os séculos.

Dessa forma, acompanhar a evolução da interpretação e tratamento dos transtornos mentais, ao longo do tempo, pode ajudar a compreender $\mathrm{o}$ atual cenário dos portadores de transtorno mental no Brasil, especialmente considerando as garantias e direitos fundamentais preconizados pela Constituição Federal de 1988 e a consequente edificação do direito à singularidade desses cidadãos².

Sendo assim, constata-se o fenômeno da loucura como uma construção histórica e social, e o direito como uma engrenagem que pode auxiliar e concretizar as políticas segregadoras e desiguais relacionadas aos transtornos mentais, quando edifica leis que respaldam o cerceamento à liberdade, limitam as singularidades, patrocinam a estigmatização e a segregação de sujeitos³.

A exclusão dos portadores de transtorno mental passa, portanto, invariavelmente pela convalidação do direito, que por suas leis e regras legalizou e edificou instituições totais ${ }^{4}$, patrocinando a rotulação e segregação de determinados sujeitos 5 .

A análise histórica dessa relação entre o direito e o fenômeno da loucura permite a compreensão mais atenta dos obstáculos, possibilidades e alternativas no tratamento e reinserção social dos portadores de transtorno mental à sociedade, uma vez que não se pode pensar a reabilitação psicossocial do portador de transtorno

\footnotetext{
${ }^{1}$ GUIMARÃES, Andréa Noeremberg et al. 0 tratamento ao portador de transtorno mental: um diálogo com a legislação federal brasileira (1935-2001). Texto contexto, Florianópolis, v. 19, n. 2, jun. 2010. Disponível em: <http://www.scielo.br/scielo.php?script=sci_arttext\&pid=S0104-07072010000200008\&lng=pt\&n$\mathrm{rm}=\mathrm{iso}>$. Acesso em: 04 dez. 2012. Passim.

${ }^{2}$ SILVA, Janaína Lima Penalva. O direito fundamental à singularidade do portador de sofrimento mental: uma análise da Lei 10.216/01 à luz do princípio da integridade do Direito. 2007. Dissertação (Mestrado). Universidade de Brasília, Brasília, 2007. Passim.

3ld. Ibid., passim.

${ }^{4}$ Para Goffman, as instituições totais são assim classificadas por representarem uma barreira na interrelação entre seus internados e a sociedade. Ao ser admitido em uma instituição como esta, o sujeito passa por um processo de despedida e recomeço. Tem seu eu mutilado com a perda do nome e da identidade social que tinha fora da instituição. Tais instituições totais podem ser divididas, em cinco grupos: os asilos, os orfanatos que existem para cuidar de indivíduos incapazes, mas inofensivos; Os sanatórios, hospícios, etc. que cuidam dos incapazes considerados uma ameaça à sociedade; As penitenciárias onde os indivíduos são encarcerados de maneira involuntária, por representarem algum tipo de periculosidade; Os quartéis, escolas internas, onde os próprios indivíduos admitem-se voluntariamente; E por fim as instituições religiosas os conventos, claustros e mosteiros, onde os indivíduos que lá estão detém uma crença em comum, e seu cerceamento de liberdade têm alguma finalidade ou razão religiosa. GOFFMAN, E. Manicômios, prisões e conventos. 7. ed. São Paulo: Perspectiva, 2005.
}

${ }^{5}$ GOFFMAN, E. op. cit. 
mental se não se conhece o contexto no qual esse cidadão está inserido e quais paradigmas, modelos e ideologias são levados em conta ao cercear a sua liberdade ${ }^{6}$.

Desse modo, é importante desconstruir as definições estigmatizantes e segregantes de que são vítimas os portadores de transtorno mental ao longo dos séculos, tendo como objetivo a busca de sua subjetividade, valorizando laços afetivos e sociais ${ }^{7}$.

Nessa perspectiva, a interseção necessária entre história, direito e saúde pode auxiliar o movimento de interpretação da atual situação dos portadores de transtornos mentais em nossa sociedade e quão longe estamos de uma solução efetiva e definitiva para a inclusão e socialização de todos os nichos da sociedade que são alijados por não se adequarem aos padrões ocidentalmente aceitos.

Não há leitura na área da saúde mental que não passe, invariavelmente, pelo Direito e pela efetivação jurídica das políticas de saúde. Também não há política na área da Saúde que não se embase nos direitos e garantias do cidadão, pois, em um Estado Democrático de Direito, pautado no superprincípio da dignidade da pessoa humana $^{8}$, não pode haver espaço para políticas públicas edificadas ao arrepio de leis e normas constitucionais protetivas.

Para pautar essas políticas públicas, então, as garantias e direitos fundamentais do cidadão devem amparar os portadores de transtorno mental com vistas a efetivar a desinstitucionalização, desospitalização, ressocialização e sua reinserção social ${ }^{9}$.

Nesse cenário, esta reflexão teórica, com base na revisão da leitura e legislação publicadas sobre o tema, apresenta como objetivo revisitar a trajetória histórico-cultural e social do tratamento dos portadores de transtorno mental, com ênfase no Brasil, realçando as significativas transformações que levaram, pelo menos em tese, um sistema pautado na referência hospitalar a um sistema interdisciplinar de atenção diversificada e comunitária. Visando atingir esse objetivo, inicialmente aborda-se a rotulação ${ }^{10}$ dos portadores de transtorno mental, destacando a dicotomização entre

${ }^{6}$ CARNIEL, Aline Cristina Dadalte. O acompanhamento terapêutico na assistência e reabilitação psicossocial do portador de transtorno mental. 2008. Dissertação (Mestrado) - Escola de Enfermagem de Ribeirão Preto, Universidade de São Paulo, Ribeirão Preto, 2008.

${ }^{7}$ Id. Ibid., passim.

${ }^{8}$ PIOVESAN, Flávia. Os direitos humanos e o direito constitucional internacional. 9. ed. São Paulo. Saraiva, 2008.

${ }^{9}$ GUIMARÃES, Andréa Noeremberg et al. op. cit.

${ }^{10} \mathrm{~A}$ palavra rotulação será empregada neste texto, no sentido da escola criminológica conhecida como Labelling Approach. Tal escola mudou o paradigma da criminologia, ao deslocar o foco do estudo das causas e motivações do comportamento desviado para as instituições de controle social. Nesta escola parte-se do paradigma que a lei penal serve para etiquetar ou rotular o indivíduo. O desviado aqui é aquele a quem se aplicou com sucesso a etiqueta de criminoso. Ou seja, o crime não tem uma natureza ontológica, mas sim é fruto de uma reação social ideologicamente e politicamente direcionada (BARATTA, Alessandro. Criminologia crítica e crítica do direito penal. 3. ed. Rio de Janeiro: Revan, 1999). Utiliza-se a mesma sistemática da reação social para estigmatizar todo e qualquer grupo social minoritário, como no caso os portadores de transtorno mental. 
"normais" e "anormais" ${ }^{11}$ fazendo um paralelo entre esse dualismo e a exclusão perpetrada aos considerados "anormais"; posteriormente, descreve-se a história da loucura e seu tratamento no Brasil, concluindo com a Lei 10.216/2001 ${ }^{12} \mathrm{e}$ as possibilidades de concretização do princípio da dignidade humana, da igualdade e da efetivação ao Direito à Singularidade ${ }^{13}$.

\section{Dualismo e a exclusão social}

Para se entender a exclusão de que foram (e são) alvo os portadores de transtorno mental ao longo dos séculos, é importante vislumbrar a dicotomização presente na sociedade entre "normais" e "anormais". Nesse sentido, o normal faz referência à norma, à regra, ao preceito que unifica e integra o diverso e reabsorve e aniquila as diferenças. O normal é um termo que deriva de instituições sanitárias e pedagógicas, cujas reformas se produzem como consequência da revolução francesa. Devido a uma exigência normatizada e exterior, o heterogêneo deve se normalizar ${ }^{14}$.

A norma, socialmente estabelecida, é um recurso disciplinador das relações sociais. O normal aqui entendido corresponde, tão somente, a um determinado critério estatístico, que se estabelece a partir do que é avaliado como desejável por uma parcela da sociedade em um determinado período ${ }^{15}$. Já o anormal corresponde à negação lógica, anterior à norma. É, portanto, o contrário do normal, o que vai de encontro ao socialmente pactuado e estabelecido. Foucault ${ }^{16}$ lembra que a norma vai admitir e proporcionar certo exercício do poder, podendo até mesmo ser considerada um conceito político.

A dicotomia "normal" versus "anormal", no entanto, não responde todas as indagações e não satisfaz o conjunto de pretensões estigmatizantes. Assim, resta necessário fundir o conceito do patológico a esse dualismo. Nessa perspectiva, Tendlarz $z^{17}$ assim afirma: "Lo patológico es definido como aquello que se aplica a la enfermidade. En realidad, lo normal se opone a lo anormal, no a lo patológico".

Canguilhem $^{18}$, ao aprofundar a discussão e explorar os limites da chamada normalidade, acrescenta os conceitos de erro, anomalia, monstruosidade, possibilitando a desconstrução do conceito de saúde. Sendo assim, o filósofo francês edifica

\footnotetext{
${ }^{11}$ TENDLARZ, Silvia Helena; GARCIA, Carlos Dante. A quién mata el asesino. Buenos Aires: Grama Ediciones, 2008. Passim.

${ }^{12}$ BRASIL. Lei no 10.216, de 06 de abril de 2001. Dispõe sobre a proteção e os direitos das pessoas portadoras de transtornos mentais e redireciona o modelo assistencial em saúde mental. Disponível em: <http:// www.planalto.gov.br/ccivil_03/leis/leis_2001/I10216.htm>. Acesso em: 15 maio 2014.

${ }^{13}$ CARNIEL, Aline Cristina Dadalte. op. cit., passim.

${ }^{14}$ CANGUILHEM, Georges. O normal e o patológico. 7. ed. São Paulo: Forense Universitária, 2011. Passim.

${ }^{15}$ TENDLARZ, Silvia Helena; GARCIA, Carlos Dante. op. cit., passim.

${ }^{16}$ FOUCAULT, Michael. A história da loucura. 7. ed. São Paulo: Perspectiva, 2004. Passim.

${ }^{17}$ TENDLARZ, Silvia Helena; GARCIA, Carlos Dante. op. cit., p. 16.

${ }^{18}$ CANGUILHEM, Georges. op. cit., passim.
} 
um conceito de saúde pautado na possibilidade de se recuperar e de se adaptar e não na mera presença de uma enfermidade ${ }^{19}$.

Ao se atribuir valor ao normal, verifica-se que esse conceito não se contrapõe unicamente ao de enfermidade ou ao irrefutável conceito de morte, mas principalmente ao conceito de "monstruosidade" 20 . Nesse contexto, de maneira dicotômica e dualista, a sociedade foi forjada na concepção "normal” versus "anormal”, adicionando-se a este último conceito as enfermidades, patologias, anomalias, monstruosidades, ou seja, tudo o que foge do padrão estabelecido. A loucura se filia à anormalidade, sendo o louco considerado improdutivo e perigoso ${ }^{21}$. Partindo de uma sociedade dicotômica e capitalista, fica evidente o papel e a sistemática do processo de exclusão e segregação desse grupo social minoritário (e improdutivo) do seio da comunidade, tanto na assistência psiquiátrica como na relação interpessoal de atenção dos portadores de transtorno mental.

Alves assim afirma:

Como um fato socialmente condicionado, a loucura culminou em uma lógica pertinente ao momento histórico de confirmação do capitalismo. Dentro da conformidade capitalista e suas cidades, a loucura passa a ser motivo de exclusão ${ }^{22}$.

Nesse embate entre "normal" e "anormal", resta ao considerado louco ser envolvido por um ambiente feito exatamente para torná-lo inofensivo e também para curá-lo de sua patologia, e os lugares construídos para essa terapêutica, como os hospícios e manicômios, aniquilam qualquer tipo de subjetividade ou individualidade.

Não obstante, fica claro que o objetivo no tratamento de portadores de transtornos mentais habitualmente foi a eliminação de um problema, a supressão de determinada parcela da população considerada improdutiva e perigosa, assemelhando-se esse sistema terapêutico ao sistema prisional ${ }^{23}$.

Ao abordar o assunto, Basaglia argumenta:

Podemos afirmar desde já que ele é, antes de mais nada, um homem sem direitos, submetido ao poder da instituição, à mercê, portanto, dos delegados da sociedade (os médicos) que o afastou e o exclui o paciente é visto como figura social sem nenhum valor e peso ${ }^{24}$.

\footnotetext{
${ }^{19}$ CANGUILHEM, Georges. op. cit., passim.

${ }^{20}$ TENDLARZ, Silvia Helena; GARCIA, Carlos Dante. op. cit., passim.

${ }^{21}$ FOUCAULT, Michael. op. cit., passim.

${ }^{22}$ ALVES, Paulo André de Lacerda. Vida social de usuários de um CAPS: a reconstrução de subjetividades. 2011. Dissertação (Mestrado) - Escola de Enfermagem de Ribeirão Preto, Universidade de São Paulo, Ribeirão Preto, 2011. p. 17.

${ }^{23}$ CARNIEL, Aline Cristina Dadalte. op. cit., passim.

${ }^{24}$ BASAGLIA, Franco. A instituição negada: relato de um hospital psiquiátrico. Rio de Janeiro: Graal, 1985. p. 107,108 .
} 
Dentro desse paradigma de exclusão, os portadores de transtorno mental historicamente foram usurpados de sua dignidade, com a ação direta de políticas públicas segregadoras, rotuladoras e estigmatizantes, sendo os direitos humanos tratados como mero conceito.

Apesar dessa realidade, é crucial apontar que a dignidade humana não pode ser reduzida à condição de mero conceito ${ }^{25}$ e deve ser efetivada em políticas públicas e também nas relações privadas. Uma vez desmistificada a construção ideológica por trás dos conceitos de loucura e transtorno mental, e denunciadas as frágeis bases para o dualismo entre "normais" e "anormais", impreterível se faz posicionar tais ideologias historicamente, visando situar a exclusão e a estigmatização no tempo e no espaço.

\section{Uma breve história da loucura}

A loucura sempre foi interpretada de diversas maneiras no decorrer da história da humanidade, de acordo com a época ou o contexto social ${ }^{26}$. Quatro séculos antes de Cristo, a loucura já era discutida e refletida entre os gregos, e Hipócrates a relacionava aos desarranjos orgânicos, ou a uma crise no sistema de humores ${ }^{27}$.

Barros-Brisset argumenta:

A doença mental é uma invenção muito recente se tomarmos, por espectro, os mais de dois mil e quinhentos anos da fundação da ciência médica com Hipócrates. Os que hoje são nomeados como loucos, portanto doentes mentais, antes, tiveram muitos nomes, desde que foi identificada a doença sagrada e os conhecidos furiosos da época hipocrática ${ }^{28}$.

Muitos séculos se passaram até a loucura assumir um lugar de destaque nas sociedades e, consequentemente, gerar maior atenção por parte dos estudiosos e pesquisadores. Apenas na idade média começamos a vislumbrar maior preocupação com a loucura, atrelada a um modelo mítico-religioso, com foco em manifestações demoníacas, possessão diabólica, heresias ou castigos divinos. Para o tratamento de tais enfermidades, a prescrição geralmente passava por cultos, orações, jejuns, culminando com o ritual de exorcismo ${ }^{29}$.

\footnotetext{
${ }^{25}$ COMPARATO, Fábio Konder. A afirmação histórica dos direitos humanos. 2. ed. São Paulo: Saraiva, 2001. Passim.

${ }^{26}$ MOREIRA, Reginaldo. Projeto Maluco Beleza: a comunicação como dispositivo terapeutizante de (re)significação de sentido de vida, no contexto da reforma psiquiátrica. 2011. Tese (Doutorado) - Escola de Comunicações e Artes, Universidade de São Paulo, São Paulo, 2011. Passim.

${ }^{27}$ FOUCAULT, Michael. op. cit., passim.

${ }^{28}$ BARROS-BRISSET, Fernanda Otoni de. Loucura, direito e sociedade um laço de presunções ideologicamente justificadas. Revista de Direito Sanitário, São Paulo, v. 12, n. 3, p. 119, 2012.

${ }^{29}$ FOUCAULT, Michael. op. cit., passim.
} 
A loucura no final da idade média (século XVII) substitui a lepra no tocante à exclusão social. Começa-se nesse período a vinculação entre portadores de transtorno mental e a periculosidade social. Não obstante, embrionariamente, as internações surgem naquela época, com o intuito de coibir a mendicância, assim como a ociosidade. A restrição de liberdade dos loucos tinha um verniz de preocupação social que a diferia, pelo menos teoricamente, das prisões ${ }^{30}$.

Devido à amplitude e alcance das medidas profiláticas daquele período, o que se vislumbrava eram estabelecimentos de internação repletos de loucos, vagabundos, desempregados crônicos, vadios, libertinos, portadores de doenças crônicas e venéreas, ou seja, toda a gama de sujeitos heterogêneos e alheios à sociedade, pessoas estigmatizadas e dispensáveis à engrenagem social ${ }^{31}$. O louco passa então a ser considerado como enfermo, o que lhe outorgou o direito à assistência e tratamento. No entanto, tal rotulação teve como efeito colateral a concretização e a consolidação da exclusão desses sujeitos da sociedade. Se por um lado o Estado lhes oferecia tratamento, por outro tais indivíduos eram então uma ameaça à tranquilidade da comunidade, não tinham mais subjetividade, direitos coletivos ou direito ${ }^{32}$. Inicia-se aqui uma escalada gradativa de exclusão e estigmatização dos portadores de transtorno mental.

Naquele mesmo século (XVII), seguindo essa ideologia crescente de exclusão e tratamento de exceção aos loucos, surgem os hospícios que, com base na sombra do tratamento e cura de uma patologia, limitavam a subjetividade do sujeito, com vistas a obrigá-lo a abandonar sua arrogância e as ideias rebeldes e condicioná-lo a mansidão e obediência ${ }^{33}$.

Sobre os hospícios da época Silva pondera:

O tratamento obedecia aos métodos mais primitivos, e os doentes, acorrentados como feras às paredes das celas, viviam em permanente posição que lhes não permitia deitar-se. Tais celas tinham a forma de uma caixa escura, sem a mínima réstia de luz nem ventilação ${ }^{34}$.

As instituições manicomiais e manicômios judiciais surgiram em resposta às novas concepções do século XVIII e sedimentaram, no ideário da sociedade, a necessidade impreterível de isolamento dos portadores de transtorno mental, como única e possível solução.

Essas instituições totais tinham em sua origem a função de rebaixar, degradar, humilhar e subtrair do indivíduo toda a liberdade e dignidade ${ }^{35}$. É importante

\footnotetext{
${ }^{30}$ FOUCAULT, Michael. op. cit.

${ }^{31}$ ld. Ibid.

${ }^{32}$ BIRMAN, Joel. A cidadania tresloucada. In: BEZERRA JÚNIOR, Benilton; AMARANTE, Paulo (Coords.). Psiquiatria sem hospício. Rio de Janeiro: Ed Relume-Dumará, 1992. p. 71-90.

${ }^{33}$ ZILBOORG, Gregory. A História de la psicologia médica. Buenos Aires: Libreria Hachette, 1945.

${ }^{34}$ SILVA, V. A. A história da loucura: em busca da saúde. Rio de Janeiro: Tecnoprint, 1979. p. 66.

${ }^{35}$ GOFFMAN, E. op. cit., passim.
} 
aqui fazer um recorte histórico do final do século XIX, com o fim de entender a exclusão social dos portadores de transtorno mental, inseridas na profilaxia médico-jurídica dominante em todo o mundo à época. Tais décadas foram marcadas pelo surgimento da eugenia, que estimulou várias políticas públicas de saúde, em um momento influenciado pela revolução industrial, pelo positivismo e mais uma série de transformações sociais e econômicas. Aquele cenário se fez propício para que a eugenia repousasse como uma esperança para a elite branca e rica ${ }^{36}$.

$\mathrm{Na}$ mesma época, surge a criminologia pelas mãos do médico italiano Cesare Lombroso e toda a fundamentação da teoria da defesa social, pautada na igualdade da lei, na legitimidade do direito e principalmente na ideia de existência de um criminoso nato, atávico e determinado biologicamente a ser um desviado ${ }^{37}$.

Enquanto isso Darwin ${ }^{38}$, desenvolvendo o evolucionismo preconizado por Spencer ${ }^{39}$, reafirmava que apenas o mais apto poderia sobreviver no embate das espécies. Contemporaneamente, o direito penal insurge com o vago conceito de periculosidade, justificador de qualquer prisão. Assim o caldo ideológico estava pronto para fomentar a exclusão de classes desfavorecidas e minoritárias, pessoas consideradas disfuncionais ou afuncionais, dentre eles os portadores de transtorno mental.

Ressaltamos que as teorias higienistas nas últimas décadas do século XIX tiveram determinante influência sobre as políticas públicas de saúde. Primeiro, em uma função oficial visavam trazer melhorias à saúde da população via tratamento das grandes doenças orgânicas; mas, de maneira não oficial, essas políticas públicas sedimentaram a aceitação e disseminação do eugenismo, entendido aqui como a eliminação das raças impuras, dos enfermos não saudáveis em prol da raça boa e "saudável"

Nesse cenário, no Brasil, os loucos ainda não haviam despertado grande interesse do Estado, nem mesmo da sociedade, até a metade do século XIX, quando alguns perambulavam pelas ruas sem incitar a sanha intervencionista. O Estado, até então, se isentava de uma participação direta nos problemas da saúde. Tais indivíduos eram afastados do convívio social. Quando pertencentes às classes abastadas eram reclusos em casa; quando pobres vagavam sem rumo, até serem recolhidos pelas casas de misericórdia ${ }^{41}$.

\footnotetext{
${ }^{36}$ SILVA, Marcos Virgílio da. Detritos da civilização: eugenia e as cidades no Brasil. 2010. Disponível em: <http:// www.vitruvius.com.br/revistas/read/arquitextos/04.048/589>. Acesso em: 15 ago. 2012. Passim.

${ }^{37}$ LOMBROSO, César. O homem delinqüente. Tradução de Maristela Bleggi Tomasini. Porto Alegre: Ed. Ricardo Lenz, 2001. Passim.

${ }^{38}$ DARWIN, Charles. A origem das espécies e a seleção natural. São Paulo: Madras, 2011. Passim.

${ }^{39}$ SPENCER, Herbert. The principles of biology. Bibliolife, 2009. v. 1. Passim.

${ }^{40}$ ROUDINESCO, Elisabeth. O paciente, o terapeuta e o Estado. Rio de Janeiro: Jorge Zahar, 2004. Passim.

${ }^{41}$ GUIMARÃES, Andréa Noeremberg. A prática em saúde mental do modelo manicomial ao psicossocial: história contada por profissionais de enfermagem. 2011. Dissertação (Mestrado) - Universidade Federal do Paraná. Curitiba, 2011. Passim.
} 
Os loucos naquele período não eram alvo de tratamentos específicos. A situação somente se modificou com a criação de hospícios a partir de 1850, mais precisamente com a construção do Hospício Dom Pedro II no Rio de Janeiro, entre os anos de 1842 e 1852. Tais instituições tiveram aqui as mesmas características do modelo europeu: isolamento combinado com exclusão e limitação de liberdade ${ }^{42}$.

Naquele período dá-se início também, em terras brasileiras, a história da psiquiatria, uma história de asilamento e, por vezes, de medicalização social ${ }^{43}$. No Brasil da metade do século XIX até os dias atuais surgiram políticas públicas das mais variadas para legitimar, direcionar e edificar posturas terapêuticas, assim como traçar políticas na área da saúde destinadas às intervenções em relação aos portadores de transtorno mental.

$\mathrm{Na}$ esteira de Goffman ${ }^{44}$, pode-se afirmar que os manicômios e hospícios, na verdade, serviam como um depositário de pessoas indesejáveis. A finalidade médica praticamente não existia, sendo a função principal dessas casas a restrição de liberdade de determinada parcela da sociedade, seu isolamento e aniquilação, ou seja, sua exclusão social.

No começo do século XX, mais precisamente em 1921, o Brasil tem seu primeiro manicômio judicial inaugurado, na cidade do Rio de Janeiro, seguindo as diretrizes do Decreto 14.83/1921, que dispunha sobre condenados que apresentassem sintomas de loucura ${ }^{45}$.

Tais instituições sintetizam e agrupam a exclusão social de portadores de transtorno mental com a de condenados por crimes ${ }^{46}$. Na década de 1930, o mundo vivia o apogeu do proibicionismo, assim como a ascensão dos regimes totalitários. As ações totalitárias dos Estados eram legitimadas por leis e pelas ciências. A autonomia e liberdade de escolha do cidadão foram desconsideradas, e a individualidade e a subjetividade foram perdendo cada vez mais espaço.

Esse Estado totalitário e centralizador abraçou as ideologias eugênicas que tiveram atuação de relevo junto à saúde pública e saneamento, assim como à psiquiatria e principalmente à "higiene mental" ao longo das primeiras décadas do século $\mathrm{XX}^{47}$. $\mathrm{O}$ isolamento compulsório assume lugar de destaque e se torna

\footnotetext{
${ }^{42}$ MACHADO, Roberto; LOUREIRO, Ângela; LUZ, Rogério; MURICY, Kátia. Danação da norma: a medicina social e constituição da psiquiatria no Brasil. Rio de Janeiro: Edições Graal, 1978. Passim.

${ }^{43}$ AMARANTE, Paulo. Asilos, alienados e alienistas: pequena história da psiquiatria no Brasil. In: AMARANTE, Paulo (Org). Psiquiatria social e reforma psiquiátrica. Rio de Janeiro: Ed. Fiocruz, 1994. Passim.

${ }^{44}$ GOFFMAN, E. op. cit., passim. SILVA, Marcos Virgílio da. op. cit. GOFFAMN, op. cit. Passim.

${ }^{45}$ CORREIA, Ludmila Cerqueira. Avanços e impasses na garantia dos direitos humanos das pessoas com transtornos mentais autoras de delito. Dissertação (Mestrado) - Universidade Federal da Paraíba, área de concentração em Direitos Humanos, João Pessoa 2007.

46JACOBINA, Ronaldo R. A prática psiquiátrica na Bahia (1874-1947). Tese (Doutorado em Saúde Pública) - Escola Nacional de Saúde Pública, Fundação Oswaldo Cruz (FIOCRUZ/MS), Rio de Janeiro, 2001. Passim.

${ }^{47}$ SILVA, Marcos Virgílio da. op. cit.
} 
protagonista dentre as ferramentas do Estado para controle da população. $\mathrm{Na}$ era $\operatorname{Vargas}^{48}$, em particular nos casos de hanseníase, o isolamento compulsório era uma medida brutal, higienista e profilática, fruto de uma legitimação científico-filosófica da fase imperialista do capital ${ }^{49}$.

Em 1934 temos o Decreto $24.559^{50}$, um diploma legal que tratou diretamente das pessoas com transtorno mental, com ênfase na profilaxia mental; assistência e proteção à pessoa e aos bens dos psicopatas; fiscalização dos serviços psiquiátricos; dentre outros aspectos.

Sobre o Governo de Getúlio Vargas, Ducatti $i^{51}$ argumenta: “a política da era Vargas garantiu ao capital o encarceramento de pessoas consideradas como não produtivas", em um claro alerta a respeito do isolacionismo que atingia determinada parcela da sociedade, formada por enfermos ou anormais.

Guimarães salienta:

Após o decreto de 1934, surgiram outras normas federais referentes à saúde mental, mas foi somente na década de 1980 que mudanças significativas de inclusão, cidadania e ética, sustentadas nos princípios da reforma psiquiátrica brasileira, tornaram-se visíveis na legislação ${ }^{52}$.

Os anos que se seguiram até a reforma psiquiátrica na década de 1970 foram marcados por políticas segregacionistas. Com o advento da ditadura militar vemos a proliferação dos hospitais particulares, e a sedimentação da indústria da loucura, principalmente a partir do final dos anos 1970. Sobre esse período Ribeiro afirma:

os donos dos hospitais privados obtinham lucros vantajosos com internações, em sua grande maioria, financiadas pelo Estado, havendo, então, um incentivo à cronificação dos pacientes desde que era lucrativo mantê-los nos hospitais ${ }^{53}$.

\footnotetext{
${ }^{48}$ Chamaremos aqui de era Vargas, aquela compreendida entre 1930 a 1945, que abrange o início do Governo de Getúlio Vargas até o final do Estado Novo. Nesta fase o Estado passa a assumir o controle da força de trabalho, incluindo também a saúde pública. 0 período foi marcado pelas ideologias totalitárias que influenciaram definitivamente as medidas de saúde, por legitimações consideradas científicas. (DUCATTI, Ivan. A hanseníase no Brasil na era Vargas e a profilaxia do isolamento compulsório: estudos sobre o discurso científico legitimador. 2009. Tese (Doutorado) - Faculdade de Filosofia, Letras e Ciências Humanas, Universidade de São Paulo, São Paulo, 2009).

${ }^{49}$ DUCATTI, Ivan. op. cit., passim.

${ }^{50}$ BRASIL. Decreto $n^{\circ} 24.559$, de 03 de julho de 1934. Dispõe sobre a profilaxia mental, a assistência e proteção a pessoa e aos bens dos psicopatas, a fiscalização dos serviços psiquiátricos e dá outras providências. Disponível em: <http://legislacao.planalto.gov.br/legisla/legislacao.nsf/viwTodos/A360611 B7E6F68F1032569FA00573BEC?Opendocument>. Acesso em: 15 maio 2014.

${ }^{51}$ Id. Ibid., p. 189.

${ }^{52}$ GUIMARÃES, Andréa Noeremberg et al. O tratamento ao portador de transtorno mental: um diálogo com a legislação federal brasileira (1935-2001), cit.

${ }^{53}$ RIBEIRO, M. B. S. Estudos de características familiares de usuários de uma associação civil para a reabilitação psicossocial. 2003. 132 p. Dissertação (Mestrado em Saúde Coletiva) - Faculdade de Medicina, Universidade Estadual Paulista “Julio de Mesquita Filho", Botucatu, 2003. p. 30.
} 
Assim, as décadas de 1930 a 1970 marcaram a consolidação do isolacionismo, com políticas públicas de saúde que perpetuaram a estigmatização e segregação dos portadores de transtorno mental, assim como os portadores de enfermidades graves e incuráveis.

Nesse período houve também a solidificação do Estado totalitário personificado na ditadura militar, na eugenia como teoria, e na busca incessante e legalizada pela profilaxia social. Diante desse Estado que consolidava a segregação e se distanciava da humanização do paciente surge como resposta à reforma psiquiátrica.

\section{Da reforma psiquiátrica à Lei 10.216/2001}

A década de 1970 foi caótica em relação ao tratamento e cuidado aos portadores de transtorno mental, que estavam alijados da sociedade, sendo vítimas de técnicas coercitivas, cruéis e desumanas, com internações que chegavam à média de 25 anos. A precariedade dos estabelecimentos, hospitais superlotados e o isolamento representavam o único método de tratamento ${ }^{54}$.

Esse cenário desolador levou à tentativa de uma mudança de paradigma no cenário terapêutico dos portadores de transtorno mental no Brasil. A reforma psiquiátrica iniciada timidamente na década de 1940 na Europa aportava no Brasil como possibilidade de solução ao caos. Por esse movimento, o doente mental poderia ser devolvido à sociedade ${ }^{55}$.

Em 1978, embrionariamente, deu-se início à reforma psiquiátrica no Brasil, com o auxílio do Movimento dos Trabalhadores em Saúde Mental (MTSM), que formulou propostas e alternativas ao sistema de isolamento e internação então vigentes ${ }^{56}$. No entanto, foi apenas na década de 1980 que tal movimento efetivamente ganhou corpo e se concretizou nas políticas de saúde no Brasil, com o redirecionamento das políticas públicas de saúde, pautadas nas internações por tempo indeterminado, isolacionistas, segregadoras e hospitalocêntricas para políticas abalizadas na cultura antimanicomial, comunitária e ambulatorial. Esse conjunto de políticas visava ao resgate do portador de transtorno mental, sua reinclusão social e à recomposição de sua dignidade ${ }^{57}$.

Naquela mesma década, juntamente com o fim da ditadura militar, tivemos o marco da desinstitucionalização, quando foram realizados a $8^{a}$ Conferência Nacional de Saúde, a I Conferência Nacional de Saúde Mental dentre outros encontros e debates. Nessas conferências ficou evidenciada a nova concepção da saúde, como

\footnotetext{
${ }^{54}$ GUIMARÃES, Andréa Noeremberg et al. O tratamento ao portador de transtorno mental: um diálogo com a legislação federal brasileira (1935-2001), cit., passim.

${ }^{55}$ BASAGLIA, Franco. op. cit., passim.

${ }^{56}$ AMARANTE, Paulo. Asilos, alienados e alienistas: pequena história da psiquiatria no Brasil, cit., passim.

${ }^{56} \mathrm{Id}$. Ibid.

${ }^{57}$ BASAGLIA, Franco. op. cit., passim.
} 
um direito do cidadão e um dever do Estado, pregando a aproximação entre usuários do sistema e a família e a inclusão da comunidade ${ }^{58}$.

Nesse quadro, o surgimento dos Centros de Atenção Psicossocial (CAPS Luis da Rocha Cerqueira, criado em 1987, na cidade de São Paulo) e do Núcleos de Assistência Psicossocial (NAPS) auxiliou na concretização de políticas públicas com o objetivo de estimular os pacientes na busca de sua autonomia e resgate de suas potencialidades com vistas a serem reintegrados à sociedade. As políticas eram embasadas na reinserção social com o objetivo de reconstruir a dignidade humana dessa parcela da população $0^{59}$.

Em 1988, tivemos a promulgação da Constituição brasileira, conhecida como constituição cidadã. O movimento de reforma psiquiátrica ganhou fôlego com essa nova Constituição, uma vez que o princípio da dignidade humana alcançou o status de garantia e direito fundamental de todo cidadão brasileiro ${ }^{60}$, ou seja, consolidou-se como um superprincípio, tendo em vista a magnitude e importância de seu alcance ${ }^{61}$.

Nesse ambiente favorável, em 1989 tivemos a primeira e efetiva experiência de desospitalização em nosso país, com o fechamento da casa de saúde Anchieta, na cidade de Santos. Nesse período fica latente a busca de uma mudança de paradigma no tratamento dos portadores de transtorno mental, com medidas visando romper com o padrão hospitalocêntrico e a busca de soluções que humanizassem o tratamento ${ }^{62}$.

Nessa esteira tivemos o Projeto de Lei 3.657, de 1989, de autoria do deputado Paulo Delgado, que, depois de uma década de debates e audiências realizadas, se tornaria a Lei 10.216/2001, estabelecendo sobre a proteção e os direitos das pessoas portadoras de transtornos mentais e redirecionando o modelo assistencial em saúde mental.

Nesse projeto de lei fica evidenciado que o leque de direitos do portador de transtorno mental consiste, dentre outras coisas, em ser atendido no melhor sistema de saúde, ser tratado com a devida humanidade, ser acolhido com respeito, visando sempre a sua recuperação no seio familiar e social, juntamente com a devida proteção contra abusos e preconceitos.

A partir de 1990 iniciam-se direta e abertamente as lutas do movimento antimanicomial no tocante às leis e atos normativos (portarias 189, 224, 407, 408, 088, dentre outras) que preconizaram importantes direitos e definiram enormes

\footnotetext{
${ }^{58}$ GUIMARÃES, Andréa Noeremberg et al. O tratamento ao portador de transtorno mental: um diálogo com a legislação federal brasileira (1935-2001), cit., passim.

${ }^{59}$ CARNIEL, Aline Cristina Dadalte. op. cit., passim.

60“Art. $1^{\circ}$ A República Federativa do Brasil, formada pela união indissolúvel dos Estados e Municípios e do Distrito Federal, constitui-se em Estado Democrático de Direito e tem como fundamentos: (...) III - a dignidade da pessoa humana;". BRASIL. Constituição da República Federativa do Brasil de 1988. Disponível em: <http://www.planalto.gov.br/ccivil_03/constituicao/constituicaocompilado.htm>. Acesso em: 15 maio 2014.

${ }^{61}$ PIOVESAN, Flávia. op. cit., passim.

${ }^{62}$ GUIMARÃES, Andréa Noeremberg et al. O tratamento ao portador de transtorno mental: um diálogo com a legislação federal brasileira (1935-2001), cit., passim.
} 
mudanças, tais como a reintegração social do portador de transtorno mental, a proibição de celas fortes nos hospitais psiquiátricos, a inviolabilidade de correspondências de pacientes e o oferecimento de mínimas oportunidades de lazer a esses ${ }^{63}$.

Embora a sociedade não tenha internalizado as mudanças efetivas da reforma psiquiátrica, as leis foram alteradas no sentido de respaldar uma humanização no tratamento dos portadores de transtorno mental.

Assim, no começo do século XXI, a Lei 10.216/2001 sintetizou as duas décadas de discussões e debates acerca dos direitos efetivos dos portadores de transtorno mental que a antecederam.

Santos afirma:

No Brasil, a já indicada Lei 10.216/2001 é um verdadeiro marco ao estabelecer a necessidade de respeito à DIGNIDADE HUMANA afeta àqueles indivíduos portadores de sofrimento mental ${ }^{64}$.

Pelo menos no aspecto teórico legal a reforma psiquiátrica ${ }^{65}$, iniciada décadas antes, se estruturou com a edição da lei preconizada por Paulo Delgado, visando modificar o panorama médico e transformar os paradigmas até então vigentes no Brasil.

Carniel argumenta que:

As mudanças havidas com a reforma psiquiátrica têm como base a reabilitação psicossocial e reintegração da pessoa portadora do sofrimento psíquico, chegando até as modalidades terapêuticas não tradicionais, como a AT, que acompanha o doente mental em sua rotina diária, resgatando, nesse, habilidade que a doença psíquica comprometera e estimulando potenciais não comprometidos ${ }^{66}$.

O autor continua continua:

No Brasil, preconceito e discriminação são partes de um processo histórico, sociocultural, fruto da origem colonial, tão presentes no cotidiano brasileiro, e de forma tão arraigada, que lutar contra eles é quase como lutar contra nossos costumes, crenças ${ }^{67}$.

\footnotetext{
${ }^{63}$ GUIMARÃES, Andréa Noeremberg et al. O tratamento ao portador de transtorno mental: um diálogo com a legislação federal brasileira (1935-2001), cit., passim.

${ }^{64}$ SANTOS, Marcos André Couto. Transtornos mentais e dignidade da pessoa humana. In: MEDEIROS, Cristiano Carrilho Silveira de (Org.). Saúde mental e o direito. São Paulo: Método. 2004. p. 51-56, passim.

${ }^{65}$ Importante relembrar a definição de Moreira (op. cit., p. 39): “A reforma psiquiátrica é um movimento advindo da reforma Sanitária, que reúne militantes indignados com a condição de abandono e de desrespeito aos direitos humanos de pessoas que adoeceram involuntariamente das suas faculdades mentais e tem como objetivo possibilitar novas formas de cuidados em saúde mental, eliminando o confinamento, a camisas de força, o eletrochoque, a lobotomia, a estrutura asilar cercada por grades e altos muros, o que dever dar espaço a abertura dos antigos manicômios".

${ }^{66}$ CARNIEL, Aline Cristina Dadalte. op. cit., p. 26.

${ }^{67}$ Id. Ibid., p. 17.
} 
Desse modo, pode-se afirmar que o modelo asilar se mostrou ao longo dos séculos uma instituição ultrapassada, arruinada e falida, pois fomentou o preconceito, a discriminação, o enclausuramento e a exclusão. Nesse contexto, a reforma veio desconstruir a ideologia do isolacionismo e da usurpação da subjetividade dos portadores de transtorno mental, o que culminou com a Lei 10.216/200168.

\section{A Lei 10.216/2001 - suas limitações e o resgate da dignidade humana}

Com a Lei 10.216/2001, a legalização da exclusão dava lugar agora (pelo menos em tese) à estruturação legal de uma rede protetiva do cidadão e da democratização de um tratamento de reinserção e reinclusão dos excluídos na tentativa de se efetivarem os direitos e garantias fundamentais preconizados pela Constituição de $1988^{69}$.

Apesar das fragilidades apontadas, pode-se afirmar que as leis do século XXI procuram desconstruir o modelo asilar e trazer novas alternativas na tentativa de modificar o atual cenário de enclausuramento arbitrário, maus-tratos, falta de higiene, abandono familiar, usurpação de direitos civis, segregação social, torturas e toda a sorte de aflições cometidas contra pessoas que têm sua liberdade restringida sem direito a ampla defesa, tampouco ao contraditório ${ }^{70}$.

Nesse aspecto vale ressaltar que a Lei 10.216/2001, embora não traga em seu texto a palavra dignidade, a garante por meio da proteção aos demais direitos do portador de transtorno mental, assegurando que todo indivíduo será tratado com humanidade e respeito ${ }^{71}$.

Essa nova concepção legal aproxima a dignidade humana dos protocolos de tratamento dos portadores de transtorno mental, contribuindo para desconstruir a estigmatização do indivíduo com transtorno mental e abolir o binômio "normal versus anormal" preconizado por Canguilhem ${ }^{72}$.

Assim, aproximando-se dos movimentos de afirmação dos direitos humanos, a Lei 10.216/2001 prioriza em seus artigos salvaguardar a dignidade humana e, consequentemente, garantir a sua subjetividade durante o tratamento, concretizando os direitos humanos dos portadores de transtorno mental ${ }^{73}$.

${ }^{68}$ CARNIEL, Aline Cristina Dadalte. op. cit., passim.

${ }^{69}$ BRITO, Emanuele Seicenti de. O direito humano à saúde mental: compreensão dos profissionais da área. 2011. Dissertação (Mestrado) - Escola de Enfermagem de Ribeirão Preto, Universidade de São Paulo, Ribeirão Preto, 2011. Passim.

70VENTURA, C. A. A. Aspectos da interface entre o Direito e a Saúde Mental. In: SOARES, Marcos Hirata; BUENO, Sônia Maria Villela (Orgs.). Saúde mental: novas perspectivas. São Caetano do Sul: Yendis, 2011. p. 175-195, passim.

${ }^{71}$ BRITO, Emanuele Seicenti de. op. cit., passim.

${ }^{72}$ CANGUILHEM, Georges. op. cit., passim.

${ }^{73}$ BRITO, Emanuele Seicenti de. op. cit., passim.

${ }^{74}$ PIOVESAN, Flávia. op. cit., passim. 
Destaca-se que a dignidade humana, aqui erigida como superprincípio ${ }^{74}$, pode ser considerada como a tentativa de efetivação e concretização de um tratamento igualitário e equânime, estendida a todo e qualquer cidadão, independentemente de cor, raça, condição social ou capacidade cognitiva, visando garantir aos sujeitos a sua individualidade, seu subjetivismo e o mínimo existencial para viverem com respeito e dignidade, para terem uma vida minimamente harmônica ${ }^{75}$.

Ao tratar o portador de deficiência com respeito e dignidade visa-se à concretização da reinserção social do paciente em seu meio, um dos objetivos principais da referida lei.

A despeito dos avanços da reforma psiquiátrica, vale ressaltar que tal reforma, assim como a Lei 10.216/, sofrem algumas limitações e críticas na sua efetividade.

Nesse aspecto, pode-se afirmar que as alterações legais não trouxeram mudanças significativas no tocante aos manicômios judiciais nem determinaram com precisão as diretrizes, sanções e políticas públicas a serem edificadas para concretizar e garantir o que a lei institui em seus artigos.

Vale ressaltar que, apesar da mudança de paradigma no tratamento dos portadores de transtorno mental nas últimas décadas, o louco infrator não se favoreceu das evoluções trazidas pela reforma psiquiátrica, não tendo os benefícios nem mesmo da Lei de Execuções Penais ${ }^{76}$. As pessoas internadas em um manicômio judicial continuaram a carregar no mínimo três estigmas: criminosas, loucas e perigosas ${ }^{77}$.

Fica claro que a reforma psiquiátrica não vem efetivando a devida reorientação das práticas assistenciais no tocante às instituições psiquiátricas custodiais ${ }^{78}$.

Outra crítica recorrente da lei de 2001 diz respeito a sua brevidade e superficialidade legislativa, composta por 13 artigos, sendo omissa ao não explanar de modo claro e preciso quais seriam as sanções e medidas repressivas àqueles que não efetivarem ou descumprirem as diretrizes do tratamento dos portadores de transtorno mental. Ademais, falta à lei maior clareza na efetividade de suas políticas públicas e maior definição da responsabilização dos agentes públicos, assim como o Estado $^{79}$.

Dessa forma, embora sejam claros alguns avanços do ponto de vista teórico-legal, o Brasil ainda padece dos males sociais e culturais em relação ao tratamento

\footnotetext{
${ }^{75}$ SANTOS, Marcos André Couto. op. cit., passim.

${ }^{76}$ BRASIL. Lei n 7.210, de 11 de julho de 1984. Institui a Lei de Execução Penal. Disponível em: <http://www. planalto.gov.br/ccivil_03/leis/I7210.htm>. Acesso em: 15 maio 2014.

${ }^{77}$ RELATÓRIO DE INSPEÇÃO HCT/BA - Ministério da Justiça, Secretaria Nacional de Justiça, Departamento Penitenciário Nacional, fev./mar. 2003. Passim.

${ }^{78}$ CORREIA, Ludmilla Cerqueira et. al. Direitos das pessoas com transtorno mental autoras de delito. Cadernos de Saúde Pública, Rio de Janeiro, v. 23, n. 9, p. 1995-2012, set. 2007. Passim.

${ }^{79}$ FIGUEIREDO NETO, Manoel Valente; ROSA, Lúcia Cristina dos Santos. A Lei da Reforma Psiquiátrica (Lei 10.216) e suas heterogeneidades enunciativas: perspectivas interdisciplinares. Âmbito Jurídico, Rio Grande, v. 13, n. 82, nov 2010. Passim.
} 
dos portadores de transtorno mental, pois ainda existem em nossas terras as velhas e ultrapassadas instituições psiquiátricas nos moldes hospitalares e asilares, e as comunidades terapêuticas que prezam pela internação e ainda pela retirada da autonomia, do individualismo e da subjetividade dos portadores de transtorno mental.

\section{Considerações finais}

Verifica-se que não há mais possibilidade em nossa estrutura legal, pautada no Estado Democrático de Direito e tendo como diretriz os princípios instituidores da igualdade e do respeito à dignidade da pessoa humana, de termos qualquer tipo de exclusão prévia de cidadãos.

A exclusão social dos portadores de transtorno mental fomenta e perpetua o dualismo segregacionista entre "normais" e "anormais", limitando ou mesmo aniquilando a subjetividade e o individualismo daqueles cidadãos que não são produtivos ou não são homogêneos diante da sociedade estruturada no sistema neoliberal.

Essa legalização da exclusão, edificada durante séculos nas políticas públicas de saúde no tocante a minorias, perdeu espaço depois da reforma psiquiátrica e de outros movimentos como a luta antimanicomial.

Desse modo, a ascensão da dignidade humana, juntamente com o princípio da igualdade, ambos preconizados pela Constituição de 1988, assumiram papel de destaque nas legislações nos últimos anos, na tentativa de equilibrar o cenário social pautado na exclusão de minorias e segregação do diferente.

Assim, com princípios pautados nos direitos e garantias fundamentais do cidadão, a Constituição Federal permitiu a quebra de paradigma na área de saúde mental, preconizando o sujeito em detrimento da segregação por sua enfermidade.

Tais medidas normativas, apontadas neste artigo, representam o primeiro passo na direção de uma sociedade mais igualitária, democrática e plural. Os movimentos de luta antimanicomial e de reforma psiquiátrica devem ser tratados como um mero início de uma árdua trajetória de desconstrução do já citado binômio "normal x anormal", e do fim da opressão e segregação social das minorias, mais especificamente dos portadores de transtorno mental.

Nessa senda, não se pode olvidar que tais leis e tais movimentos não são perfeitos e são passíveis de críticas, como a que os acusam de se omitir diante da perpetuação das medidas de segurança, os manicômios judiciais, assim como o respaldo que a Lei 10.216/2001 deu às internações compulsórias.

Portanto, sofremos de duas crises principais no cenário social que obstam a real inserção dos portadores de transtorno mental no seio da comunidade. A primeira delas é a crise de efetividade das normas, que também podemos chamar de crise eficácia, pois, embora tenhamos modificado toda a teoria e toda a legislação referente 
ao tratamento e reinserção social dos portadores de transtorno mental, o que se vê no dia a dia é a perpetuação das práticas segregacionistas e estigmatizantes. Essa crise anômica leva as letras da Constituição a não gozarem de aplicabilidade prática.

A segunda crise é a de responsabilidade, em uma sociedade que não se responsabiliza pelos doentes, velhos, crianças, jovens e portadores de transtorno mental; modificações legais não são suficientes para mudar toda a engrenagem social vigente.

Assim, deu-se o primeiro passo com a modificação da lei, possibilitou-se a instrumentalização da mudança. Contudo, não se pode esperar que tais alterações e tal quebra de paradigma fiquem apenas nas letras frias da lei.

Os portadores de sofrimento mental não devem se igualar ou se subjugar aos considerados "normais", mas sim a sociedade deve encontrar maneiras e instrumentos de conviver e respeitar as diferenças.

A igualdade social, a dignidade da pessoa humana, a cidadania, a singularidade e o respeito à subjetividade de cada um só podem ser realmente efetivados quando forem respeitadas as diferenças, e para esse respeito é impreterível que o Estado assuma de vez o papel de protagonista dessa mudança, por meio de políticas públicas práticas, conscientização, sanções e diretrizes eficazes para reinserção das minorias.

A caminhada para a conquista da cidadania por toda a sociedade passa impreterivelmente pelo respeito à singularidade do portador de transtorno mental com a valorização de suas habilidades e a possibilidade de efetivar laços sociais.

\section{Referências}

ALVES, Paulo André de Lacerda. Vida social de usuários de um CAPS: a reconstrução de subjetividades. 2011. Dissertação (Mestrado) - Escola de Enfermagem de Ribeirão Preto, Universidade de São Paulo, Ribeirão Preto, 2011.

AMARANTE, Paulo. Asilos, alienados e alienistas: pequena história da psiquiatria no Brasil. In: AMARANTE, Paulo (Org). Psiquiatria social e reforma psiquiátrica. Rio de Janeiro: Ed. Fiocruz, 1994.

(Coord.). Loucos pela vida: a trajetória da reforma psiquiátrica no Brasil. 2. ed. Rio de Janeiro: Ed. Fiocruz, 1998.

BARATTA, Alessandro. Criminologia crítica e crítica do direito penal. 3. ed. Rio de Janeiro: Revan, 1999.

BARROS-BRISSET, Fernanda Otoni de. Loucura, direito e sociedade um laço de presunções ideologicamente justificadas. Revista de Direito Sanitário, São Paulo, v. 12, n. 3, p. 119-124, 2012. 
BASAGLIA, Franco. A instituição negada: relato de um hospital psiquiátrico. Rio de Janeiro: Graal, 1985.

BIRMAN, Joel. A cidadania tresloucada. In: BEZERRA JÚNIOR, Benilton; AMARANTE, Paulo (Coords.). Psiquiatria sem hospício. Rio de Janeiro: Ed Relume-Dumará, 1992. p. 71-90.

BRITO, Emanuele Seicenti de. O direito humano à saúde mental: compreensão dos profissionais da área. 2011. Dissertação (Mestrado) - Escola de Enfermagem de Ribeirão Preto, Universidade de São Paulo, Ribeirão Preto, 2011.

CANGUILHEM, Georges. O normal e o patológico. 7. ed. São Paulo: Forense Universitária, 2011.

CAPELLARI, Marcos Alexandre. O discurso da contracultura no Brasil: o underground através de Luiz Carlos Maciel (c. 1970). 2008. Tese (Doutorado) - Faculdade de Filosofia, Letras e Ciências Humanas, Universidade de São Paulo, São Paulo, 2008.

CARDINALI, Cintia Santarém. O novo regime jurídico das medidas cautelares no processo penal. Disponível em: <http://www.emerj.tjrj.jus.br/serieaperfeicoamentodemagistrados/ paginas/series/4/medidas_cautelares_102.pdf>. Acesso em: 15 ago. 2012.

CARNIEL, Aline Cristina Dadalte. O acompanhamento terapêutico na assistência e reabilitação psicossocial do portador de transtorno mental. 2008. Dissertação (Mestrado) - Escola de Enfermagem de Ribeirão Preto, Universidade de São Paulo, Ribeirão Preto, 2008.

COMPARATO, Fábio Konder. A afirmação histórica dos direitos humanos. 2. ed. São Paulo: Saraiva, 2001.

CORREIA, Ludmila Cerqueira. Avanços e impasses na garantia dos direitos humanos das pessoas com transtornos mentais autoras de delito. Dissertação (Mestrado) - Universidade Federal da Paraíba, área de concentração em Direitos Humanos, João Pessoa 2007.

et. al. Direitos das pessoas com transtorno mental autoras de delito. Cadernos de Saúde Pública, Rio de Janeiro, v. 23, n. 9, p. 1995-2012, set. 2007.

DARWIN, Charles. A origem das espécies e a seleção natural. São Paulo: Madras, 2011.

DUCATTI, Ivan. A hanseníase no Brasil na era Vargas e a profilaxia do isolamento compulsório: estudos sobre o discurso científico legitimador. 2009. Tese (Doutorado) - Faculdade de Filosofia, Letras e Ciências Humanas, Universidade de São Paulo, São Paulo, 2009.

FIGUEIREDO NETO, Manoel Valente; ROSA, Lúcia Cristina dos Santos. A Lei da Reforma Psiquiátrica (Lei 10.216) e suas heterogeneidades enunciativas: perspectivas interdisciplinares. Âmbito Jurídico, Rio Grande, v. 13, n. 82, nov 2010.

FOUCAULT, Michael. A história da loucura. 7. ed. São Paulo: Perspectiva, 2004.

GOFFMAN, E. Manicômios, prisões e conventos. 7. ed. São Paulo: Perspectiva, 2005. 
GUIMARÃES, Andréa Noeremberg. A prática em saúde mental do modelo manicomial ao psicossocial: história contada por profissionais de enfermagem. 2011. Dissertação (Mestrado) - Universidade Federal do Paraná. Curitiba, 2011.

et al. O tratamento ao portador de transtorno mental: um diálogo com a legislação federal brasileira (1935-2001). Texto contexto, Florianópolis, v. 19, n. 2, jun. 2010. Disponível em: $<$ http://www.scielo.br/scielo.php?script=sci_arttext\&pid=S0104-07072010000200008\&ln $\mathrm{g}=\mathrm{pt \& nrm}=$ iso $>$. Acesso em: $04 \mathrm{dez} .2012$.

JACOBINA, Ronaldo R. A prática psiquiátrica na Bahia (1874-1947). Tese (Doutorado em Saúde Pública) - Escola Nacional de Saúde Pública, Fundação Oswaldo Cruz (FIOCRUZ/ MS), Rio de Janeiro, 2001.

LOMBROSO, César. O homem delinqüente. Tradução de Maristela Bleggi Tomasini. Porto Alegre: Ed. Ricardo Lenz, 2001.

MACHADO, Roberto; LOUREIRO, Ângela; LUZ, Rogério; MURICY, Kátia. Danação da norma: a medicina social e constituição da psiquiatria no Brasil. Rio de Janeiro: Edições Graal, 1978.

MOREIRA, Reginaldo. Projeto Maluco Beleza: a comunicação como dispositivo terapeutizante de (re)significação de sentido de vida, no contexto da reforma psiquiátrica. 2011. Tese (Doutorado) - Escola de Comunicações e Artes, Universidade de São Paulo, São Paulo, 2011.

PIOVESAN, Flávia. Os direitos humanos e o direito constitucional internacional. 9. ed. São Paulo. Saraiva, 2008.

RELATÓRIO DE INSPEÇÃO HCT/BA - Ministério da Justiça, Secretaria Nacional de Justiça, Departamento Penitenciário Nacional, fev./mar. 2003.

RIBEIRO, M. B. S. Estudos de características familiares de usuários de uma associação civil para a reabilitação psicossocial. 2003. 132 p. Dissertação (Mestrado em Saúde Coletiva) - Faculdade de Medicina, Universidade Estadual Paulista “Julio de Mesquita Filho”, Botucatu, 2003.

ROSA, Alexandre Morais da. O papel do juiz garantista e a execução penal em tempos neoliberais: Eichmann e Big Brother. In: CARVALHO, Salo (Org.). Crítica à execução penal. Rio de Janeiro: Lumen Juris, 2007, p. 319-348.

ROTELLI, Franco; LEONARDIS, Ota de; MAURI, Diana. Desinstitucionalização, uma outra via. In: NICÁCIO, Fernanda (Org.) Desinstitucionalização. São Paulo: Ed. Hucitec, 1990.

ROUDINESCO, Elisabeth. O paciente, o terapeuta e o Estado. Rio de Janeiro: Jorge Zahar, 2004.

SANTOS, Boaventura de Souza (Org.). Reconhecer para libertar: os caminhos do cosmopolitivismo multicultural. Rio de Janeiro: Civilização Brasileira, 2003.

SANTOS, Marcos André Couto. Transtornos mentais e dignidade da pessoa humana. In: MEDEIROS, Cristiano Carrilho Silveira de (Org.). Saúde mental e o direito. São Paulo: Método. 2004. p. 51-56. 
SILVA, Janaína Lima Penalva. O direito fundamental à singularidade do portador de sofrimento mental: uma análise da Lei 10.216/01 à luz do princípio da integridade do Direito. 2007. Dissertação (Mestrado) - Universidade de Brasília, Brasília, 2007.

SILVA, Marcos Virgílio da. Detritos da civilização: eugenia e as cidades no Brasil. 2010. Disponível em: <http://www.vitruvius.com.br/revistas/read/arquitextos/04.048/589>. Acesso em: 15 ago. 2012.

SILVA, V. A. A história da loucura: em busca da saúde. Rio de Janeiro: Tecnoprint, 1979.

SPENCER, Herbert. The principles of biology. Bibliolife, 2009. v. 1.

TENDLARZ, Silvia Helena; GARCIA, Carlos Dante. A quién mata el asesino. Buenos Aires: Grama Ediciones, 2008.

VENTURA, C. A. A. Aspectos da interface entre o Direito e a Saúde Mental. In: SOARES, Marcos Hirata; BUENO, Sônia Maria Villela (Orgs.). Saúde mental: novas perspectivas. São Caetano do Sul: Yendis, 2011. p. 175-195.

WACQUANT, Loïc. Punir os pobres: a nova gestão da miséria nos Estados Unidos. Trad. Nilo Batista. Rio de Janeiro: Revan, 2001.

ZEMISCHLANY Z.; MELAMED Y. The impossible dialogue between psychiatry and the judicial system: a language problem. Isr J Psychiatry Relat Sci, v. 43, n. 3, p. 150-158, 2006.

ZILBOORG, Gregory. A história de la psicologia médica. Buenos Aires: Libreria Hachette, 1945.

Rubens Correia Junior - Mestrando em Ciências pela Escola de Enfermagem de Ribeirão Preto, Universidade de São Paulo, e Centro Colaborador da Organização Mundial da Saúde para o desenvolvimento de pesquisa em enfermagem. Professor na Pós-Graduação em Criminologia da Pontifícia Universidade Católica de Minas Gerais; Professor de Direito Penal e Processual Penal da Universidade Presidente Antonio Carlos. Coordenador do curso de Pós-Graduação em Criminologia do Instituto Paulista de Estudos Bioéticos e Jurídicos. Pesquisador do Grupo de Estudos e Pesquisas em Enfermagem, Saúde Global, Direito e Desenvolvimento da Universidade de São Paulo. Membro da comissão de Direitos Humanos da OAB/MG. Niterói/RJ, Brasil. Blog: http://rubenscorreiajr.blogspot.com.br

Carla Arena Ventura - Professora Associada da Escola de Enfermagem de Ribeirão Preto da Universidade de São Paulo. São Paulo/SP, Brasil. 